\title{
Return on Investment of an On-site Employee Health Clinic in Multinational Information Technology Company in India
}

Name of company and research group: Department of Academics, RECOUP Neuromusculoskeletal Rehabilitation Centre, Bangalore, India.

\section{Introduction}

The ratio of the profit gained or lost relative to the cost of achieving the profit is calculated as return on investment (ROI). There are three categories of return on investment (ROI): internal, external, and social [9]. Internal ROI refers to benefits that save the organization money when developing products or services. This can take the form of decreased development costs, preventing the need for redesign, and reduced time in getting the product to market. External ROI refers to benefits that increase the profitability of products or services by making them better for the customer. This can take the form of increased sales, increased market share, decreased customer support and service costs, decreased return rate, and improved user experience. It should be noted that Internal ROI typically must be demonstrated before External ROI can be realized. Social ROI refers to the perception that human factors \& ergonomics initiatives are beneficial and can affect both Internal and External ROI. Internal Social ROI includes the perception of stakeholders that a given initiative provides a benefit, which in turn, increases management "buy in." External Social ROI consists of customer's positive perceptions of the organization due to past satisfactory experiences and demonstrated trustworthiness, which leads to improved branding and strengthened corporate image. Economic analysis, shows that the performance benefits alone that may accrue from using ergonomic work pacing software indicate a return on investment of around 3 months [1].

The reason to invest in ergonomic products or solution is to improve the health, safety, quality of life and productivity of the employee and reducing the cost of medical compensation and lost workday [3, 4, $6,11]$. In this paper authors considered 'ROI' as improvements to physical health and psychosocial factors. Literature reported that the computer - related injury, costs to an organization on an average from $\$ 8,000$ to $\$ 35,000$ in direct medical and indemnity expenses, depending on the severity and treatment of the injury [8]. Indirect costs are associated with lost productivity, training of temporary or permanent replaced employees, reduced morale (affects the quality of life), and other [13].

In organizations with IT-smart IT and business leaders, ROI is acceptable or great (93\%), business leaders drive business change associated with ITenabled investments $(90 \%)$, and IT products and services meet the needs of the business ( $88 \%$ ) [12].

The on-site clinic, for the population it serves, has a positive effect on all of the programming in the grid. As long as the employer appropriately links the clinic, its staff, and the record keeping functions, this is the one catalyst that can improve the impact of almost every other employee benefit program [5].

Several models currently exist to calculate Return on Investment (ROI) that may be used for Ergonomic interventions [2, 4, 7]. All of these approaches are based on evaluating the costs and benefits of the 
intervention. There are studies that calculated ROI of different intervention studies. But there is scarcity of studies which explains the ROI on Ergonomic intervention implemented on the IT professional in India. Keeping that in mind this study was formulated to measure the ROI on a specific ergonomic intervention (onsite clinic).

\section{Methodology}

The on-site clinic consists of performing workstation evaluation, diagnosis of WRMSDs by physicians and therapists, followed by treatment using Ergonomic modifications and a sequenced protocol designed by RECOUP for preventing WRMSD. The advantage of the on-site clinic is that inventor appoints one therapist to be available every day at the company so that employees have the ease of accessing this service. As a third party inventor had no access on the employee's wages, absenteeism, productivity and other quantitative assessment. Therefore, in this study improvement of quality of life in terms of pain perception and self reported productivity were taken as outcome measurements. To evaluate the pain perception the participants were asked to rate their body discomfort on a body discomfort chart in $10 \mathrm{~cm}$ VAS scale before of the intervention. The same readings were collected after completion of the intervention as well. The self reported Productivity was also evaluated by comparing the responses before and after the intervention. The data were collected from 150 employees participated from different multinational IT company.

\section{Result}

In this study total cost of intervention in the company includes nominal wages (Rs. 15,000.00 per month) to the Therapists / Ergonomists for performing the assessment and treatment plus in some cases addition of accessories (keyboard tray, mouse tray) but in $95 \%$ of these cases success was achieved by just adjusting the existing components of the workstation. The benefits include reduced complaints of pain and discomfort leading to increase in productivity and decrease in absenteeism in the employees. After completing the on-site program, $95 \%$ of employees reported no pain and that their productivity increased.
Therefore, for 150 employees (approx. wages Rs. 180.00 per hour) with an investment of one therapist employed, the productivity increased by a conservative estimate of $20 \%$ based on employee feedback. With this data, an approximate amount of Rs. 25,000.00 per worker per annum was saved by the company because of the intervention. Improvement in the pain level is presented in table 1 .

Table 1.

Comparison of pain intensity before and after the intervention

\begin{tabular}{lllll}
\hline Before & After & t-value & $\begin{array}{l}\text { Level of } \\
\text { significance }\end{array}$ \\
\hline $7.89( \pm 1.10)$ & $3.37( \pm 1.42)$ & 13.11 & $\mathrm{P}<0.05$ \\
\hline
\end{tabular}

The participants informed about the improvement in the quality of life in terms of personal and professional. They informed in the improvement in the duration of seating at a stretch. Improvements in the daily activities were reported by the participants. Comfortable working conditions, improvement in the sleep were also reported by the participants. Many cases improvement in the concentration also recorded for the participants.

\section{Discussion}

Although authors were interested in calculating the ROI of this service but we do not have access to data such as wages, reported lost work time due to WRMSD, and medical compensation as the company would not disclose this information.

Before the intervention, the particular company had complaints from the employees of pain and discomfort and demanded for better furniture. The companies spent conventional ergonomic chairs which are ranging from Rs. 2000 to Rs. 20,000 but the problems was still remained. The net-cost model provides a comprehensive tool for evaluating returns from an Ergonomic intervention and was used in several companies which had employed interventions in reducing low back pain (LBP). The model essentially defines net cost as investment cost on intervention equipment plus labor cost involved in implementing the intervention minus avoidable healthcare cost of illness and injury, productivity losses due to loss in efficiency and absenteeism, and other benefits due to the productivity enhancement. All costs are calculated 
per annum. For calculating the net cost, data from the pre- and post-intervention time needs to be collected, such as the duration of the kind of pain/disability, number of missed days of work, and average salary of the employees with pain. Also, information on decrease in productivity due to pain and increase in efficiency after the intervention will be required. Although comprehensive, the model is difficult to be applied to certain companies where the data on medical care cost and salary of the employees cannot be disclosed as is the case with many companies in India.

Although implicated, this may be a conservative estimate as we assumed some minimum values for data that were missing. It is required to design a study to evaluate the accurate ROI of the on-site clinic by making modifications to the existing ROI models and extracting relevant data (loss of time due to work, percentage increase in productivity, medical costs) from the employees and the company.

From a company/organization's point of view, the primary reason to invest in Ergonomic interventions (i.e. participatory programs, Ergonomic furniture, physiotherapy etc) is to get return on investment (ROI), such as increase in the productivity, decrease in the medical complaints filed, and decrease in the leave of absence and so on. The present study could establish that an ergonomic intervention in terms of on-site clinic reduced the pain intensity and improved self reported productivity.

\section{References}

1. Alan H., Effects of Ergonomic Management Software on Employee Performance, Department of Design and Environmental Analysis, 1999

2. Goggins R.W., Spielholz P., \& Nothstein G. L. Estimating the effectiveness of ergonomics interventions through case studies: Implications for predictive costbenefit analysis, Journal of Safety Research, 2008, 39, $339-344$.

3. Hughes R.E., and Nelson N. A., Estimating investment worthiness of an ergonomic intervention for preventing low back pain from a firm's perspective, Applied Ergonomics, 2009, 40, 457-463

\section{Author: Deepak Sharan ${ }^{1}$}

Address for correspondence $:{ }^{1}$ RECOUP Neuromusculoskeletal Rehabilitation Centre, \#312, 80 Feet Road, 10th Block, Further Extension of Anjanapura Layout, Bangalore-560062, India

Corresponding author, Email ID: deepak.sharan@recoup.in
4. Lahiri S., Gold J., and Levenstein C., Net-cost model for workplace interventions, Journal of Safety Research, $2005,36,241-255$.

5. LaPenna A.M., Workplace Clinics and Employer Managed Healthcare A Catalyst for Cost Savings and Improved Productivity, CRC Press, Taylor \& Francis, 2010.

6. Norman R. and Wells R., Ergonomic Interventions for Reducing Musculoskeletal Disorders: An Overview, Related Issues and Future Directions, Department of Kinesiology Faculty of Applied Health Sciences University of Waterloo Waterloo, ON, Institute for Work \& Health, 1998.

7. Oxenburgh M. and Marlow P., The Productivity Assessment Tool: Computer-based cost benefit analysis model for the economic assessment of occupational health and safety interventions in the workplace, Journal of Safety Research, 2005, 36, $209-214$

8. Vischer J.C., The effects of the physical environment on job performance: towards a theoretical model o $\mathrm{f}$ workspace stress, Stress and Health, 2007, 23, 175-184.

9. Wilson C.E., and Rosenbaum S., Categories of return on investment and their practical implications. In R.G. Bias and D.J. Mayhew (Eds.), Cost-Justifying Usability: An Update for the Internet Age San Francisco, CA: Morgan Kaufman Publishers, 2005, 215 - 263.

10. Www.cos-mag.com

11. www.eighthates.com

12. WwW.rsiguard.com 